\title{
Sustainable Development and Well-Being: A Philosophical Challenge
}

\author{
Mollie Painter-Morland ${ }^{1,4}{ }_{(\mathbb{C})} \cdot$ Geert Demuijnck $^{2} \cdot$ Sara Ornati $^{3}$
}

Received: 31 May 2016/ Accepted: 26 July 2017 / Published online: 10 August 2017

(c) The Author(s) 2017. This article is an open access publication

\begin{abstract}
This paper aims at gaining a better understanding of the inherent paradoxes within sustainability discourses by investigating its basic assumptions. Drawing on a study of the metaphoric references operative in moral language, we reveal the predominance of the 'well-being $=$ wealth' construct, which may explain the dominance of the 'business case' cognitive frame in sustainability discourses (Hahn et al. in Acad Manag Rev 4015:18-42, 2015a). We incorporate economic well-being variables within a philosophical model of becoming well (Küpers in Cult Organ 11(3):221-231, 2005), highlighting the way in which these variables consistently articulate a combination of 'objective' and 'subjective' concerns. We then compare this broad understanding of well-being with the metaphors operative in the sustainable development discourse and argue that the sustainability discourse has fallen prey to an overemphasis on the 'business case'. We proceed to draw on Georges Bataille to challenge the predominance of these value priorities and to explore which mindshifts are
\end{abstract}

Mollie Painter-Morland

mollie.pm@ntu.ac.uk

Geert Demuijnck

geert.demuijnck@edhec.edu

Sara Ornati

sara.ornati@ntu.ac.uk

1 Management Division, Nottingham Business School, 50

Shakespeare Street, Nottingham NG1 4FQ, UK

2 EDHEC Business School, 24 Avenue Gustave Delory, CS 50411, 59057 Roubaix Cedex 1, France

3 Economics Division, Nottingham Trent University, 50 Shakespeare Street, Nottingham NG1 4FQ, UK

4 IEDC-Bled School of Management, Bled, Slovenia required to develop a more comprehensive understanding of what is needed to enable 'sustainable development'.

Keywords Sustainable development · Well-being · Metaphor · Georges Bataille

\section{Introduction}

In this paper, we investigate some basic assumptions inherent in discourses around sustainable development in order to better understand its current paradoxes and impasses. Our analysis draws on Hahn et al.'s (2015a) description of two distinct normative frames within sustainable development discourses, i.e. the 'business case frame' and the 'paradoxical frame'. The 'business case frame', which characterizes much of what is written in corporate sustainability, pursues a 'utility'-based instrumentalist and often short-term justification for integrating social and environmental concerns within a firm's business operations. The 'business case' frame is, however, more complex than is often acknowledged. Since profit-seeking remains a central part of the rationale for sustainability, many have become preoccupied with showing how social and environmental efforts 'pay-off' (Painter-Morland and ten Bos 2016). Others have argued that 'legitimacy seeking' rationales are even more important to companies and more helpful in implementing sustainability initiatives than profit-seeking rationales (Schaltegger and Hörisch 2015).

Whether pursued for profit or legitimacy, the 'business case' rationale has its limitations in terms of the pursuit of sustainable development. 'Corporate sustainability' should be distinguished from 'sustainable development'. Examples of arguments for 'corporate sustainability' abound. For instance, Gómez-Bezares et al. (2016) analysed the impact 
of CSR on market shares for FTSE 350 companies during the period 2006-2012. The main finding of the paper is that 'investing in companies with corporate sustainability not only generates higher returns during peak phases, but also diminishes shareholders' losses during bear phases'. In contrast to this strategy of corporate profit maximization or financial risk management through sustainability strategies, 'sustainable development' is a normative concept outlining desirable development paths in societies, with an interest in ensuring intergenerational justice (Hahn et al. 2015b, p. 298). This is especially important since the level of analysis (societal-organizational-individual) and the timeframes (short vs. long term) directly impact the motivation for, and implementation of sustainability initiatives. Different levels of analysis and different time-frames often lead to paradoxical tensions and contradictory impulses. We join Hahn et al. (2015b) in arguing that sustainable development can only be meaningfully addressed in corporations if the paradoxical tensions and contradictions that lie inherent in corporate sustainability are acknowledged. We will argue that George Bataille's political economy provides important perspectives in doing so. In fact, we believe that he challenges us to fully articulate these contradictions.

To highlight the way in which the 'business case' frame has become dominant in corporate sustainability discourses, we will study some of the metaphors and reveal the assumptions that they harbour. The study of metaphors in organizational contexts is widely acknowledged as a valuable way to gauge the tacit belief structures operative in organizations (Morgan 1980; Alvesson 1993; Milne et al. 2006; Cornelissen et al. 2008; Hart 2008; Audebrand 2010; Tay 2010). Studying metaphors in the area of sustainable development helps us develop an understanding of how certain moral conceptions come into existence, how they are related to our real embodied experience of the world (Johnson 2007), and how they now guide our thinking and argumentation within sustainability discourses. We therefore aim to provide an analysis of both the cognitive-linguistic dimensions of metaphor and the discursive functioning of metaphors (Cornelissen et al. 2008).

Below we argue that the understanding of 'well-being' that the 'business case' draws on is too narrow, especially within sustainability discourses that have to take into account the complexities of people's subjective desires. We will consider the various definitions of well-being that have emerged in the literature and show how they consistently articulate a combination of 'objective' and 'subjective' concerns, long-term and short-term variables, and different analytic foci (individual, group and systemic). We also draw attention to the centrality of subjective well-being and its relationship to individual autonomy and societal flourishing in these definitions. When one compares the metaphors operative in sustainability discourses with these conceptions of 'well-being', an impoverished understanding of 'wellbeing' is revealed. The metaphors used in sustainability discourses implicitly assume the model of homo economicus, the rational agent who directs his/her own course towards well-being through rational calculative decision-making. In fact, a kind of 'moral accounting' scheme often informs the pursuit of sustainable business practices. In many cases, this leads to a failure to adequately consider the implications of particular business practices for 'subjective well-being', which are crucial to support concerns for the environment and social responsibility. Recognizing this over-reliance on moral accounting may overcome some of the limitations of our current approaches towards sustainability.

We would like to offer our reading of some of Georges Bataille's writing on political economy as a starting point for thinking through these issues. ${ }^{1} \mathrm{We}$ believe that some of Bataille's ideas on political economy offer important insights on the relationship between what economist describes as 'objective need' and 'subjective desire'. In this way, he might help us further unpack the paradoxes and tensions that exit within Hahn et al.'s (2015a) 'paradoxical' framing of sustainable development. His ideas in this regard challenge us to reconsider some of the basic assumptions that inform our understanding of sustainable business practices. Prima facie, Bataille's vision on the economy may lead to pessimistic conclusions with respect to calculative sustainability, but, more importantly, it helps us understand that the pursuing a sustainable economy is far more complex than then the current common metaphors suggest.

\section{Conceptions of 'Well-Being'}

Lakoff and Johnson (1999) draw on cognitive science research to argue that one of the most basic cognitive structures of our moral language is what they describe as the 'Well-being is wealth' construct. Our basic bodily need for well-being makes it inevitable that an increase in wellbeing is defined as a gain, and any impediment to wellbeing as a loss, or a cost. The system of moral accounting that underlies our way of approaching moral questions is quite intricate and shapes our expectations of each other. Consider the following everyday phrases: we 'invest' in relationships, or 'profit' from hard work. Lakoff and Johnson (1999, Kindle edition Chapter 14 Location 7743)

\footnotetext{
${ }^{1}$ Bataille was a French intellectual, who came to prominence in the mid-twentieth century. He was close, among others, to prominent philosophers such as Sartre, Merleau-Ponty, Klossowski and Hyppolite. Many of these scholars had a background in philosophy, as well as a broad knowledge of the literature, social sciences, ethnology, psychoanalysis, etc. In their writings, they brought all of this to bear on some of the pressing ethical and politico-economic concerns of their times.
} 
go further to argue that by that decreasing someone's wellbeing, one also incurs a certain moral debt, for instance you owe someone an apology for an insult. Much in the way that economic transactions depend on financial bookkeeping, we implicitly rely on moral bookkeeping. This 'moral bookkeeping' system demands some form of reciprocation, i.e. the possibility of retribution or revenge, or restitution or reparation. It should therefore come as no surprise that it is very difficult for us to get beyond calculative thinking when it comes to morality, as is also evident in the 'business case' cognitive frame (Hahn et al. 2015a). The 'right' thing to do is to increase well-being, and the 'wrong' thing to do is to diminish it. A reliance on some notion of 'moral accounting' informs our acceptance of moral arguments regarding the acceptability of 'trickle-down economics' or beliefs in the power of the 'invisible hand'. As long as something works to increase well-being/wealth, it is morally acceptable. In what follows, we offer an analysis of various conceptions of 'well-being' to better understand what is perceived as 'wealth'. More specifically, we bring economic conceptions of well-being in conversation with a philosophical understanding of being well, combining subjective and objective, and individual and collective dimensions (Küpers 2005).

What we found is that a materialistic bias initially seems to have informed the exploration of the 'wellbeing = wealth' cognitive frame. It led researchers to focus on the analysis of the relationship between materialism and well-being, anticipating the existence of a positive relationship between those two variables. In the economic literature, the term 'happiness' has historically been used as a synonym for 'welfare' and 'well-being'. Happiness is defined as social welfare, a concept much broader than just economic well-being (Abramovitz 1959). Easterlin's (1974) main result is that in developed countries people reported levels of happiness that did not significantly correlate with GDP. This is referred to as the 'Easterlin Paradox', i.e. well-being does not increase with an increase in monetary wealth, and has been found to exist in various international contexts (Blanchflower and Oswald 2008).

Indeed, well-being measures even appear to be negatively related to consumerism and overconsumption (Christopher et al. 2009; Miesen 2009; Burroughs and Rindfleisch 2002). From a social perspective, it is widely acknowledged that overconsumption has a negative impact on social welfare and it is unsustainable. Indeed, it depletes resources at higher rates, causes the accumulation of waste on landfills and generates pollution during the production stage. Therefore, even if beneficial in the short term (higher production leads to higher employment rates), it is counterproductive in the long term, generating intergenerational justice issues as well.
A lot of research has been devoted to studying the impact of different variables on well-being (Graham 2008; Graham et al. 2004; DeNeve and Oswald 2012). Some studies compare conceptions of 'well-being' in different national contexts. These studies have found a remarkable degree of convergence in the variables that different national populations associate with 'well-being' (Chuluun et al. 2014). These variables include health, income, employment, stable partnerships and social relationships. Interestingly, income is considered important only up to a certain threshold (Chuluun et al. 2014). When individual income is extremely low, it tends to have a negative impact on people's well-being. Consequently, a rise in income only improves the well-being of individuals with a low level of income.

In simple terms, people only enjoy a sense of well-being if they have food security, are free from persecution and have a safety net to fall back on (Dolan and Metcalfe 2012). Graham (2008) argues that the main variable affecting people's happiness is their own health and not their individual income. Indeed, respondents reported wellbeing is affected by expectations of their own health and the correlation between happiness and health is more statistically robust than that between happiness and income. According to Sen (1999): 'the fulfillment of these needs help provide people with the capabilities to flourish as human beings'. As such, the satisfaction of certain 'objective needs', which is related to having the basic means of livelihood and good health (which are often related), has always been a core component of 'well-being'. However, after income reaches a certain threshold, further increases in personal income do not increase well-being, but other variables start playing a significant role. For example, an individual's income relative to those of others starts to have an important impact on his/her sense of well-being (Chuluun et al. 2014). Burroughs and Rindfleisch's (2002) main finding is consistent with the social welfare view, where individuals who internalize social values more than individual materialistic ones enjoy a higher well-being. On a similar note, Vansteenkiste et al. (2006) show that subjective well-being is positively related to social values and relationships, while materialism and its different forms (wealth, possessions) has no impact on it.

The idea that well-being includes 'subjective' and nonmonetary variables has gained widespread consensus (Graham and Nikolova 2013; Diener 2012). According to Graham (2010), an advantage of using 'subjective' measures of well-being is that respondents can have their voices heard by expressing their personal opinions. Frey and Stutzer's (2002) main finding is that self-reported satisfaction depends heavily on non-monetary variables, such as social capital and good governance. Ryan and Sapp (2007) explain that: 'subjective well-being concerns a 
person's capacity for optimal functioning, a confidence in being able to formulate and act to fulfil important goals and the motivation and energy to persist in the face of obstacles'. Cognitive evaluations of one's life, happiness, satisfaction, positive emotions such as joy and pride, and negative emotions such as pain and worry all form part of one's experience of 'subjective' well-being. Stiglitz et al. (2009) have therefore proposed that each of these 'subjective' variables should be measured separately to derive a more comprehensive appreciation of people's lives.

This discussion echoes earlier philosophical discussions related to the methodological assumptions of economic theory and the broader utilitarianism debate. Within economics, utility is typically defined as the degree of satisfaction of preferences, and the latter are considered as given data (the preferences as they are 'revealed' in the choices of sovereign consumers), that do not deserve any further discussion. The title of a famous article of George Stigler and Gary Becker, defending this methodological assumption, is unsurprisingly 'De Gustibus Non Est Disputandum' (Stigler and Becker 1977). ${ }^{2}$

However, Griffin (1991) has argued that, although this simplification may make sense for explanatory of predictive purposes, it misses the point as a concept of wellbeing. According to Griffin, well-being is the fulfilment of 'informed desires', not of whimsical preferences. That means the subjective preferences should not only be rational in a formal sense (which means that an ordering of preferences should be complete, transitive, etc.) but also in a broader sense: they have to be understandable as valuable. That means that we have to be able to understand the preferences against the background of general human aims (Griffin 1986, p. 51). The economist's way of considering preferences starts from the idea of 'consumer sovereignty', according to which things are valued because they are desired. A normative approach of rational preferences necessarily has to reject this 'taste-model' (Griffin 1991). People have preferences for one option over another because on the basis of an independent valuation of these options. It starts from the idea that things are desired because they are valued by the subjects, and our values are not purely capricious or a mere matter of taste. Among the authors who, like Griffin (1991), defend the latter position we can further distinguish between authors who defend the idea that what people value is 'subjective' and authors who claim that there is an 'objective list' of elements that people should value. In other words, there is an ongoing philosophical debate about how well-being should be conceived that is not clarified at all. But, as van der Deijl (2017) has recently convincingly demonstrated, this

\footnotetext{
2 For an excellent overview and clarification of the confusions around utility and well-being in economic theory, see Hausman (2012).
}

disagreement among philosophers about how well-being should be conceived does, surprisingly, allow to some extent the measurement of well-being. This is related to the fact that philosophers and social scientists-who try to measure well-being-despite their conceptual disagreements, agree on some general principles about well-being: for example, there is an agreement about the principle that well-being is subject-dependent: roughly, what is good for someone's life depends on what the person values. And secondly, they all agree there is an epistemic limitation: people are not always the best sources to judge their own well-being. The acceptance of these principles allows us to make some sense of the measurement of well-being, despite underlying disagreements on well-being as a philosophical concept (van der Deijl 2017).

In order to assess what people actually value, Summers and Smith (2014) draw on the Millennium Ecosystem Assessment (MEA 2005). They include the following variables in their assessment of 'subjective' well-being: choice, solastalgia (distress caused by environmental change around one's home), community vitality, access to nature, affection/respect towards nature, cultural requirements, happiness, freedom, topophilia/sense of place, identity, social cohesion, access to diverse nature, access to leisure, aesthetics. There is a strong emphasis in this list on a sense of agency, as well as persistence and coherence over time. As Dolan and Metcalfe (2012) emphasize, agency, social norms, virtues and behaviours can either determine subjective well-being or be generated as a result. Therefore, in order to correctly evaluate the policy implications of subjective well-being, the direction of the causality process plays a central role. It is of outmost relevance to be able to understand the various dimensions of subjective well-being, in terms of behaviours and social norms, because 'from the perspective of subjective wellbeing, agency, social norms, virtues and individual behaviour are only important in so far as they have the ability to change the experiences of people's lives' (Dolan and Metcalfe 2012).

As Hahn et al. (2015b) indicate, one must take account of the different levels of analysis and time dimensions if one wants to understand sustainability. We believe that this categorization offers a helpful starting point to better understand the well-being dimensions that may tacitly influence our sustainability discourses. Hahn et al.'s (2015b, p. 301) analysis highlights the importance of acknowledging various levels of analysis (societal, organizational, individual), time dimensions (long vs. short term), etc. If we were to plot the various variables that we discussed above based on the typical level of analysis that is at stake, and time dimensions that are in play, the paradoxes would become clear. For example, where does one place 'income' on the short-term or long-term axis? 
Where would 'loneliness' fall on the axis that depicts individual, social or systemic concern? The purpose of such an analysis would be to show how important it is to acknowledge that these different analytical foci lead to often paradoxical tensions when it comes to understanding not only sustainability, as Hahn et al. argue (2015a), but also well-being $=$ wealth, which is a core cognitive frame that shapes moral discourses.

In his philosophical exploration of well-being, Küpers (2005, p. 226) acknowledges this complexity and proposes a more inclusive, practice-oriented approach that would allow us to investigate the complex, interrelated processes involved in understanding well-being. Küpers describes these processes as 'the integral pheno-practice of well-being'. 'Pheno' refers to phenomenological approach that aims to describe how subjects experience and make sense of their 'Lebenswelt'. His proposal of analysing the integral pheno-practice of well-being draws on advanced phenomenology that views subjective, intersubjective and objective dimensions as part of a process of interrelational becoming well, which unfolds over time and displays many paradoxical tensions.

The process character of becoming well may help us understand why short-term and long-term, individual and social dimensions have to be included in any understanding of well-being. Graham (2012) categorization of hedonic well-being, which represents 'how people assess their daily experiences', would be categorized as short term, and their descriptions of 'evaluative well-being', which represents 'how people assess their lives as a whole', would be long term. The former is extremely specific, and in surveys, it is analysed with the use of questions about positive and negative things that respondents experience in their lives, whereas the latter is assessed with the use of questions related to life satisfaction as a whole. In order to assess hedonic well-being, respondents are requested to provide information about 'the emotional quality of their everyday experience', that is to say 'the frequency and intensity of experiences of joy, stress, sadness, anger, and affection that make one's life pleasant or unpleasant' (Kahneman and Deaton 2010). On the other hand, in order to assess lives as a whole, respondents are asked about the 'thoughts they have about their life when they think about it' (Kahneman and Deaton 2010). Evaluative well-being incorporates a measure of eudamonia, i.e.: 'how much purpose there is in people's lives'. Income and education are good predictors of life satisfaction, whereas health, care giving, loneliness and smoking better predict daily emotions (Chuluun et al. 2014). Empirical evidence shows that evaluative well-being matters more for individuals with more means and agency, and the reverse is true for hedonic well-being (Graham and Nikolova 2013). Küpers (2005, p. 222) also investigates on the distinction between hedonism and eudaimonism and comes to the conclusion that subjective hedonic and social and eudaimonic dimensions both contribute to our understanding of well-being as an unfolding interrelational process.

In Fig. 1, we use Küpers' model of 'becoming well' as an integral pheno-practice to map the multiple well-being variables that emerge from economists' analysis of wellbeing.

What becomes clear is that 'well-being' can be described as a combination of 'objective' and 'subjective' variables that can only be understood by using different levels of analysis. The dominance of variables in the 'culture' quadrant is of particular interest. We will now investigate how the various dimensions of well-being are reflected in sustainability discourses in order to unpack the ways in which strictly objectivist calculative thinking cover over the inherent paradoxes within sustainability discourses. We then explore how a Bataillian analysis may help us understand the interaction between well-being variables that operate across quadrants.

\section{Sustainable Development Metaphors}

\section{Metaphors and Valuation}

If 'sustainable development' is to be defined in the way the Brundtland report has done, i.e. as meeting our current needs without compromising the ability of future generations to meet their needs (WCED 1987), then the way in which 'needs' are conceptualized is key to imagining sustainable business strategies. One can only develop an understanding of 'needs' that is related to our conceptions of well-being, if the tacit normative parameters that underpin it can be revealed. The idea goes back to at least Nietzsche: our understanding of the world is mediated by language, and metaphors are an important linguistic tool that plays an immense role in the way in which we 'construct' reality, and also morally desirable realities. However, as Nietzsche pointed out, metaphors live their own way and people become unaware of the fact that they are metaphors in the first place, like 'used coins' on which the face of the king they represent is no longer visible (Nietzsche 1886/1973). Metaphors reveal some aspects of reality (that is why they use them), but they hide at the same time perspectives that other metaphors could have revealed. Insofar as we are mostly unaware of the metaphorical character or our use of language, we are likely to forget that our way of thinking and our way of seeing things is largely perspectival. Many scholars in organization studies have explored the fundamental role, be it constructive or ambiguous, of metaphors in management (Cornelissen et al. 2008). An important distinction around 
Fig. 1 Economic well-being variables from the perspective of a pheno-practice of becoming well. [Authors' own, adapted from Küpers (2005)]

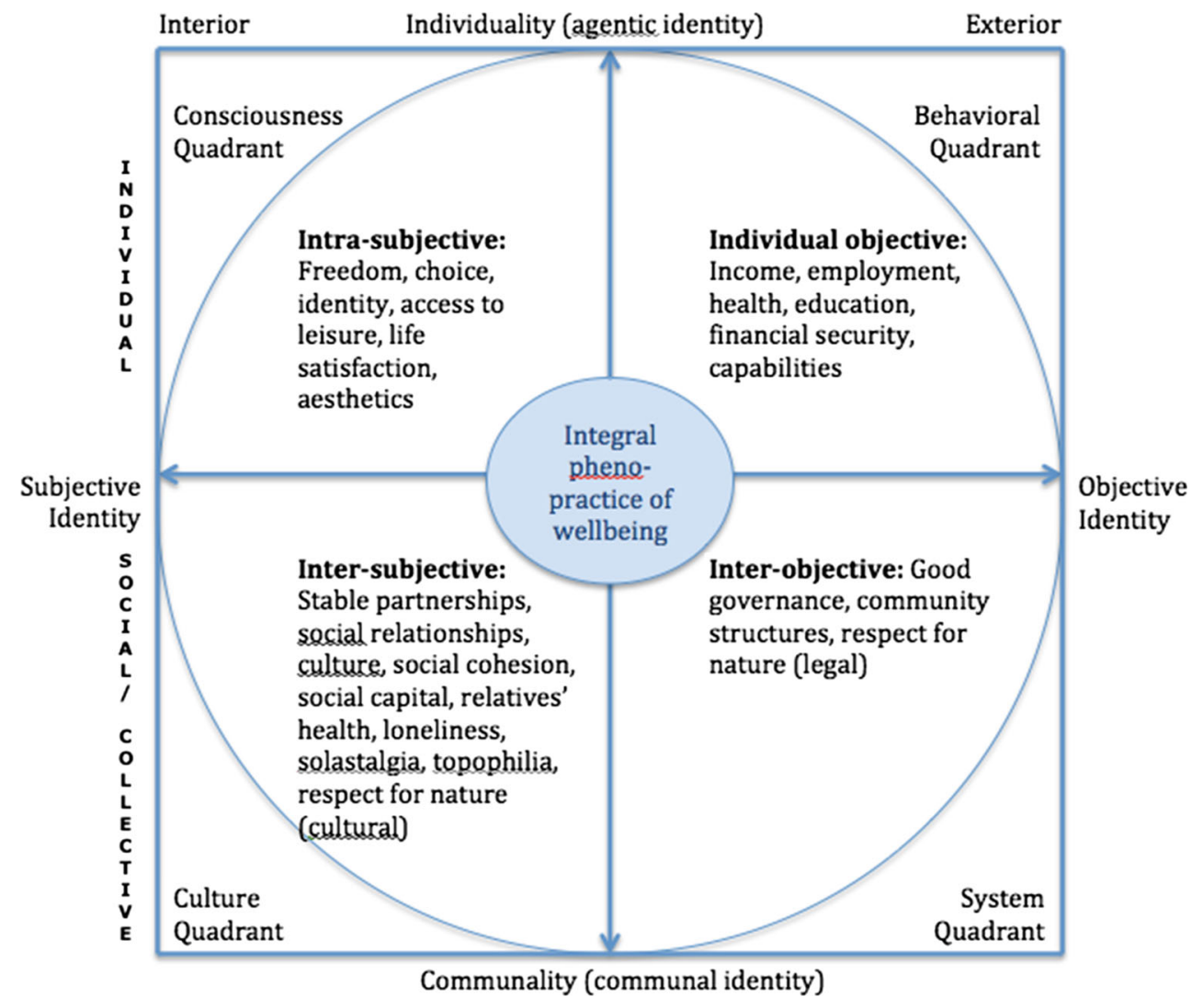

the analytic form that metaphors take is the difference between a contextual, cognitive-linguistic approach to metaphors and a contextual, or 'discourse'-based approach to metaphors (Cornelissen et al. 2008, p. 9).

The first approach considers, in the way in which we presented Nietzsche's reflections on metaphors above, metaphors as tools of thought that organize our experience, as 'patterns of thinking' that appear in different contexts, that structure our perspective on reality in a way we are largely unaware of. The second approach examines how specific metaphors are used in specific contexts and 'actively employed to 'manage' interests in social interaction' (Cornelissen et al. p. 13). Both approaches are not necessarily mutually exclusive, but the perspective is different. The first approach suggests a metaphorical mapping of the mind in which we are trapped and the second a manipulative use of metaphors to defend interests. The way in which metaphors crop up in the sustainability discourse suggests that both approaches are relevant.

\section{Well-Being $=$ Wealth as a Root Metaphor}

When we looked at the metaphors operative in sustainability discourses, we highlighted well-being = wealth as a dominant cognitive-linguistic root metaphor, which is linked to a whole range of other metaphors used in existing contextual discourses, which may elicit, or foreclose certain insights around sustainability. From the cognitive-linguistic perspective, the metaphors within the corporate sustainability discourse help us understand certain cognitive proclivities around well-being and wealth. This is important since well-being $=$ wealth, as a 'root' metaphor, informs our most basic forms of understanding and as such helps us gauge what is considered to be of value and how this is measured and pursued. Audebrand (2010) defines root metaphors as follows: 'Root metaphors make up the ultimate presuppositions or frames of reference for discourse on the world or a domain within it'. Corporate sustainability's calculative mindset persists because of the existence of root metaphors of which the content has become distorted. In the case of the 'business case for sustainability', corporate sustainability perpetuates the implicit understanding that wealth has to be understood as monetary wealth.

\section{Natural Capital}

Within the corporate sustainability discourse, one of the most dominant contextually operative discursive metaphors is that of 'natural capital'. With this metaphor comes a range of other assumptions. The 'root metaphor' that the notion of 'natural capital' draws on is related to the cognitive-linguistic structure that well-being $=$ wealth: 
capital can be stored, built up through investment, used instrumentally, or it can be depleted, or lost. It therefore needs to be measured, managed and manipulated through instrumental procedures and rationales. From a discursive perspective, the metaphor 'natural capital' was proposed with the best intensions, i.e. as a 'boundary object' to create common ground between diverse actors and assert the importance of the protection of the environment as a non-negotiable condition for flourishing. However, if it covers over certain cognitive prejudices, such as that wellbeing is related to monetary wealth, it can also become a hegemonic concept (Akerman 2005, p. 45). It can surreptitiously serve to entrench calculative practices and calculative agency and, in doing so, make it harder to think about the environment in any other terms (Blewitt 2005, p. 72$)^{3}$

When one looks at the cognitive assumptions that 'natural capital' make, and relate it to the root metaphor of well-being $=$ wealth, the notion of 'natural capital' seems to gloss over the real differences between financial capital and natural capital. It has been proposed that this danger could be obviated by refining the use of related metaphors. Gough (2005, p. 97), for instance, argues that the exploratory power of the metaphor of 'natural capital' is in tension with its explanatory power. Financial stock's value is at any given time $(t)$ taken to be the net present value of the total flow of benefits as at $t$, plus the benefits which it is expected to provide in future, minus the costs (the corresponding value of any present or future costs) associated with maintaining the stock in being. But 'natural capital' does not operate in the same way, largely because the relevant present knowledge may be irreducibly incomplete and the degree of uncertainly of the value is dramatically higher than in the case of the stock market (Gough 2005, p. 98). Gough (2005, p. 99) goes on to argue that employing the notion of 'real options' as a sub-metaphor to deal with 'natural capital' makes much more sense because it can accommodate this uncertainty and complexity. In sustainability marketing, reference is sometimes made to the 'living product'. This also represents an attempt to deal with the uncertainty of dynamic and flexible natural configurations (Mitchell and Saren 2008). In our view, these mitigation strategies are ultimately still subject to an implicit calculative scheme of 'moral accounting'. It does little more than acknowledge the inherent complexity involved in such calculative endeavours.

In her analysis, Akerman (2005, p. 38) proposes that the 'natural capital' metaphor influences the rules according to which claims about sustainable development can be made, as well as the way in which the objects of environmental

\footnotetext{
3 And even in these calculative terms, the metaphor seems to be misappropriated, as Winnett (2005, p. 87) convincingly argues.
}

knowledge are constituted. The notion of 'natural capital' evokes two very different images of nature, i.e. as a financial asset and as an ecosystem. However, the former of these images, with its implicit link to monetization, has gradually begun to predominate. As a result, the meaning of the concept of 'natural capital' has narrowed within the field of corporate sustainability. It has come to denote a kind of 'productive machinery' (Akerman 2005, p. 46). In its wake, various calculative practices based on the presumption of biophysical and monetary competition have emerged. The dominance of this calculative thinking has essentially marginalized other ways of expressing the relationship between humans and nature (Akerman 2005, p. 48).

\section{Industrial Ecology}

The ascendence of calculative thinking in the field of corporate sustainability is also associated with the introduction of another metaphor: 'industrial ecology' (Hess 2010). The precise relation between biological ecosystems and industry is, of course, far from unambiguous. Hess (2010, p. 271) therefore argues that it is important to distinguish between the ecosystem as a model and the ecosystem as a metaphor. Understood as a model, an ecosystem's various underlying representations are simply not all amenable to transposition. For instance, the circular way in which one agent's waste serves as another's resource within natural ecosystems does not necessarily correspond to industrial systems' linear model of manufacturing, consuming, storing, or discarding. Hess (2010, p. 274) argues furthermore that regularity, abundance, and diversity are not necessarily properties of industrial symbiosis, nor of companies, which are after all not natural organisms. By drawing attention to the significantly different implications of understanding 'industrial ecology' as either a metaphor or a model, Hess encourages a more considered employment of this, and other metaphors within the field of sustainable development. Valuable as this may be, it does not really seem to have the power to propel our discourses beyond the gravitational pull of calculative thinking.

The ascendence of calculative thinking is evident in the predominance of utilitarian arguments in the moral justification of business behaviour. The oft-touted 'business case for CSR', which is an instance of 'corporate' or 'weak' sustainability, is a familiar case in point. In a similar vein, corporate philanthropy is advocated as a way of creating 'moral capital' for the firm. This has led to an attempt to rationalize philanthropy as a form of 'enlightened self-interest'. This is done by means of tying philanthropy directly to strategy, or by embedding philanthropic activities more explicitly within a defined 
CSR strategy. The paradoxical effect of this is that the more firms become 'socially responsible', the more the discretionary scope of philanthropy is limited (Spence and Thompson 2009, p. 373). Within the realm of 'strategic philanthropy', there is also an intense preoccupation with measurement technologies. The result is that whatever cannot be measured and reported on is deemed valueless. Corporations also extract surplus value from their participation in philanthropic activities and mine the emotional commitment of various stakeholders to particular causes to help build their brands (Spence and Thompson 2009, p. 385). All of this may be taken as indications of the extent to which an insidious kind of 'moral accounting' has become normalized within business communities in recent times.

There is an implicit conflation between monetary wealth and moral wealth in this kind of instrumental reasoning. It provokes moral contempt for any perceived form of waste, as this entails a loss of wealth and well-being. Furthermore, it creates intolerance for anything that cannot be justified in instrumental financial terms. Spence and Thompson (2009), for instance, have drawn attention to some of the moral impasses thrown up by business' 'pathological profit-seeking' and unwillingness to contribute to anything unless it yields some sort of business benefit. They point out how justifications for so-called corporate philanthropy are inevitably predicated on the notion of 'the deserving poor'. The fact that charities have to prove that their constituencies 'deserve' corporate largesse is clearly incoherent and inappropriate within the context of 'altruistic' giving. Similar paradoxes may be observed within the field of sustainable development. Banerjee (2008a, p. 58), for instance, argues that the efficiency-legitimacy dichotomy within corporate sustainability discourse often becomes problematic because legitimacy is subordinate to efficiency.

What effectively happens is that 'notions of legitimacy are discursively produced and defined by economic efficiency criteria' (ibid.). It seems therefore that a preoccupation with effective growth of wealth, especially in terms of private property, has come to shape contemporary attitudes towards sustainable development. However, given some of the problematic implications associated with this approach, the time may have come to reconsider some of the assumptions that inform our understanding of sustainable development.

A critical reassessment of the tacit 'well-being equals wealth' construct that seems to inform so much contemporary thinking about sustainable development is a good place to start. The equation of well-being with wealth is problematic in both directions: on the one hand, the pervasive preoccupation with calculability that shapes our language tends to preclude other possible conceptions of well-being. On the other hand, the use of ecological metaphors obscures the differences between flourishing, as it is experienced within the context of the non-human world, and the accumulation of financial wealth. In fact, associating industrial ecology with natural ecology, and financial capital with natural capital, may serve only to perpetuate misconceptions about the true objectives of business activity. The problem seems to lie on two levels: (1) the calculative mentality that pervades contemporary thinking about sustainable development and (2) the fact that calculations are almost exclusively performed in pecuniary terms, and more likely to focus on the individual, rather than collective level.

However, these problems are ultimately no more than the inevitable implications of a much more basic set of common assumptions regarding the nature of human agency. In many business communities, 'homo economicus' remains an implicit and largely unchallenged orthodoxy. If human beings are, as subscribers to this orthodoxy suppose, essentially rational, calculative and self-interested individuals, whose actions follow from careful consideration of their own economic interests, then it stands to reason that they should employ rational, financial calculation in their approach to sustainable development. However, this account of human agency largely ignores experienced forms of 'subjective well-being' that may influence the perceptions and behaviour of individuals and groups. It cannot meaningfully accommodate the interaction between subjective and objective and individual and collective well-being variables. It also underscores the assumptions inherent in the discursive employment of metaphors.

\section{The Journey Metaphor}

A prominent metaphor that has been deployed within current sustainability discourses is the 'journey' metaphor, which is an excellent example of the discursive approach to metaphor. Milne et al. (2006) start from the observation that in the debate about sustainability we can easily distinguish between scholars-and business people-who defend 'weak sustainability', that is the idea that sustainability will be realized through incremental improvements in which business will explore eco-efficiency and ultimately find win-win strategies that combine sustainability with profitability, and other scholars who argue that sustainability can only be reached on the basis of a far more radical change of our economic and social system. According to the latter, an incremental approach is hopelessly insufficient to reach sustainability: we have to end growth in human (demographic) and economic terms. Milne et al. (2006) observe that the surprisingly frequent use of the metaphor 'journey' to characterize the transition 
towards sustainability allows to weaken the tension between short incremental business initiatives and the radical requirements of a sustainable human civilization on earth. They illustrate how the use of this metaphor (by business people and international organizations in particular) reassures society insofar as it suggests many things at the same time and equally hides some other aspects. 'Journey' suggests that we are on our way, that there is a commitment, and it assumes implicitly that economic development and the planetary constraints can be reconciled at some point. It simplifies the picture and, in fact, distracts our attention from the real decisions that should be made right now. The authors judge the journey metaphor as dangerous insofar that insufficient changes will be made. However, although the ambiguous role of the metaphor is convincingly demonstrated, the authors argue merely that it conveniently allows business people avoiding fundamental discussions that would question the legitimacy of their business activities, but they do not explicitly argue that business people have actively been using this metaphor to legitimize continuing business as usual. The metaphor plays an ideological role, but no ideology creator is identified. At most, we could conclude that the paper makes an implicit 'cui bono' conspiracy argument: business people unconsciously perpetuate certain root metaphors that fit in with their financial interests, especially since these are hardly ever challenged.

Audebrand (2010) proposes that we should, from the perspective of strategic management, consciously search for powerful metaphors, that is, metaphors with a high heuristic value that will lead to creativity and innovation. On the other hand, Audebrand argues, we should stop using metaphors, like the prevailing 'war' metaphor, that narrow our mindset and that do not allow integrating sustainability in strategic management. In a similar vein, we believe that Bataille can be helpful in understanding why certain metaphors, as cognitive-linguistic structures, as well as the discursive use of metaphors towards certain purposes, fail to help us to further meaningful sustainable actions. We believe that some assumptions that current metaphors make around well-being $=$ wealth misinterpret what human beings really value and how we become well. With Küpers (2005, p. 228), we argue that well-being is not something that individuals 'have', but that instead emerges out of the communal interplay and interchange between individuals, communities and their environments. In what follows therefore, we begin to explore a conception of human agency that does not require us to deny or gloss over the complexities of subjective, interrelational experience. We offer this conception of 'non-calculative sovereignty' as an alternative to homo economicus' calculative autonomy. We believe that its capacity to include, rather than exclude the important role of subjective experience in human behaviour ultimately makes it a more appropriate conceptual basis for thinking about sustainable development.

\section{Reconsidering the 'Well-Being Equals Wealth' Equation}

\section{Bataille's Political Economy as Challenge to Conceptions of Utility}

Although Bataille himself considered his work as an economist (in La notion de dépense, and La part Maudite) as his most important work, it has never been taken seriously by economists (with one exception ${ }^{4}$ ). This is easy to understand if one considers the radically different viewpoint Bataille develops. Jean Baudrillard succinctly observed that Bataille 'attacked the metaphysical principle of the economy' (Baudrillard 2010, p. 149). Bataille did so by posing a fundamental challenge to the scope of the concept of 'utility'. The conception of the market economy that informs most contemporary textbooks is based on the assumption that economic agents (be they consumers, producers, employers, employees, etc.) are rational utility maximizers. Such agents maximize the satisfaction of their preferences by weighing up alternative choices, cutting costs, optimizing output with given input, maximizing profit, permanently calculating and optimizing against given parameters or against the changing strategies of competitors in a complex market environment. Moreover, these rational agents save and invest, i.e. they optimize in a context of risk and uncertainty, which implies that they always focus on the future. In Bataille's description of capitalism, he draws attention to its participants' pervasive obsession with 'utility' (in the more narrow sense of 'usefulness'). The logic that follows from this obsession dictates that spending should be limited to useful things that will contribute to future benefits. Although this is not Bataille's wording, we believe that the well-being $=$ wealth metaphor is implicit in the mainstream way of conceiving the economy, or in Bataille's vocabulary, the 'restrictive' economy.

From Bataille's perspective, most people have come to see the capitalist economy as the pursuit of well-being through wealth (materialistically defined), both in theory and in practice. However, there is, according to Bataille, another not really hidden, but rarely recognized dimension to the economy. A narrow focus on the rational maximization of utility obscures what Bataille sees as the real sources of human motivation and well-being, much of which we could situate at the interface of the consciousness

\footnotetext{
4 The exception is Francois Perroux. See Guillaume (1987) for a discussion of the reception of Bataille as an economist.
} 
and culture quadrants of Fig. 1 (Cf. supra). Bataille studied anthropology and was aware of the fact that even in archaic civilizations the economy produced much more than people actually needed to survive. This surplus production allowed the 'sacrificial expenditure' of resources-including human labour and lives. Surplus resources were often consciously depleted, destroyed, consumed, wasted or squandered without any consideration of utility. One may of course argue that this only occurred in primitive economies like the ones described by anthropologists like Malinowki or by the Jesuits who described the Aztec culture, but not in the contemporary capitalist system. And indeed, Bataille argued that the typical bourgeois in the capitalist economy is characterized by what he calls a 'servile' attitude: all decisions are considered in terms of future benefits. Everything is carefully calculated and optimized. However, what ultimately really mattered in primitive economies were precisely those moments when calculation, anticipation of the future and considerations of utility played no part in shaping the behaviour of groups or individuals. Bataille insisted that this is also true of our own time, though it may be harder to recognize or admit. Little wonder that he gave the title 'Au-delà de l'utile', (beyond usefulness) to a draft version of 'The Accursed Share'-the book in which he developed these ideas. Bataille sees this transgression of what he calls the 'utility constraint' as something positive. For him, it is a liberation from servility. He therefore uses the metaphor, 'sovereignty' to describe it. For him, there is something almost miraculous and sacred in this disregard of utilitarian constraints. Like a king, people act sometimes as if they were beyond calculation and servility. In this sense, the discursive employment of Bataille's description of 'sovereignty' redefines the root metaphor of well-being = wealth, embracing 'wealth' from a general perspective. This would involve a sense of detachment from the cost cutting, optimizing and calculating utility-maximizing attitude of the homo economicus.

The self-avowed objective of Bataille's theoretical project is a general critique of the ideas that subordinate human activities to aims different from the useless consummation (sometimes erroneously translated as consumption $^{5}$ ) of their resources. He wants to destroy those ways of seeing that justify 'servile forms' (our translation, Bataille's italics 1976, p. 10). We should note here that the French word that we translate as 'consummation' has the connotation (according to Larousse) of 'the action of destroying something, progressively or totally, like by fire'. So, the point is not necessarily to consume in a hedonistic way (although hedonism is not systematically absent, even

\footnotetext{
5 Sometimes Bataille defines consummation as unproductive consumptions. Cf. Bataille (1976: 12).
}

in Bataille's examples); it is rather that the expenditure or the destruction of the resource serves no further purpose. It is in that sense that it is a sovereign 'consummatory' act. It has a kind of 'intrinsic' value - a value in, and of, itself. It neither requires nor submits to utilitarian justification. For Bataille (1976, p. 11), a system in which everything is compelled to submit to the tyranny of utilitarian calculation, and nothing is 'sovereign', is ultimately absurd.

Bataille (1991) therefore criticizes bourgeois power's preoccupation with scarcity, productivity, frugality and instrumentality/utility. This concern with utility in capitalist bourgeois societies found a powerful partner in Christianity's advocacy of hard work and frugality (Taylor 2004, p. 316). Bataille argues that capitalism's unrelenting utilitarian imperatives effectively forced human beings into servility. The frivolous, useless and dangerous were gradually marginalized and ostracized. A convergence of economic, social, legal and moral power was required to create and sustain this system. Bataille draws our attention to some of the latent tensions in contemporary capitalist societies: male bourgeoisie regularly transgress their own calculative edicts in acts of war and luxurious expenditure. For Bataille, these are essentially consummatory acts of sovereignty. In turning to a prostitute, for instance, the bourgeois man turns to something beyond the systems of usefulness. He luxuriates in a kind of wasteful expenditure, which is an act of consummatory sovereignty inasmuch as it serves no purpose beyond itself. The widespread fascination with the figure of the criminal (consider here the plethora of popular TV shows focused on crime) may also be attributable to its apparent wanton destruction and wasteful expenditure of property and lives. Similarly, the wars of the twentieth century are instances of catastrophic expenditure, which followed the excessive growth and expansion brought about by industrial capitalism. In Dorfman's (2002, p. 38) reading of Bataille, 'Our fantasies, silences and immoralities are products of the limited nature of the real, the articulated and the moral'.

\section{Bataille's Relevance to Sustainability Debate}

Maybe the easiest way to catch the starting point of Bataille's vision on the economy consists of taking a look at the monthly supplement of the Financial Times with the unapologetic title 'How to spend it' (http://howtospendit.ft. com). In this supplement, you find advertisements for extravagantly expensive watches, yachts, fabulous vacation resorts, private jets, etc. These pages are particularly addressed to people who spend their working day inventing cost-cutting measures, arbitrage on financial markets, investing, optimizing and managing. That is, perfectly 'servile' activities. And yet, these people seem fascinated by the idea of spending huge resources just for fun. Bataille 
(1976, pp. 248-253) offers a number of other examples of 'sovereign' behaviours. He describes driving around in a car, for instance, on what he calls a 'contemplative journey'. This may be strange nowadays but one has to imagine what it meant in the 1950s to drive around in the French countryside in an act of 'contemplation'. This activity is completely unrelated to the conventional 'use' or 'usefulness' of a car. It is not directed towards the future. Instead it is an act of complete presence in the moment without a defined aim (Bataille 1976, p. 253). For Bataille, 'sovereignty' is fundamental to being human: to feel free to do or refrain from doing whatever one likes/dislikes, to be completely absorbed in one's experience of a moment, to remain unperturbed by any particular aim or concern for the future (Bataille 2011, pp. 181-182). ${ }^{6}$

Bataille's distinction between a 'general' and a 'restrictive' economy is helpful in understanding our preoccupation with pecuniary calculation. The 'restrictive economy' focuses on the scarcity of resources within a particular system and as such supports the conventional model of rational, utilitarian exchange between profitmaximizing economic agents. Bataille's alternative notion of a 'general economy', however, focuses on the excess of energy (wealth) within a broader economic system. As such, the general economy also encompasses those resources that are available for sovereign consummation within an economic system, including the social, the sexual or the sacred. From this 'general' perspective, we may understand 'poverty' as the inability to 'consummate' the resources that are produced in the economy, rather than the inability of the economy to produce enough resources for 'consumption' (Bataille 1991, p. 39). Bataille's analysis allows us to recognize that the widespread corporate aversion to waste is informed by a 'restrictive' economic perspective. From this perspective, the corporation's agents feel compelled to make productive use of what they perceive as 'scarce resources', in order to benefit the corporation and its immediate stakeholders. The scarcity motive enhances and perpetuates the calculative impulse, which operates in the 'business case' for sustainability. It mandates that investments always yield measurable financial benefits. It compels individual and corporate actors to rationalize their actions by means of careful cost-benefit analysis.

Typically, the 'business case for sustainable development' has to be made convincingly before corporations are prepared to commit themselves to it. Corporations want to see how social investments will translate back into financial gain, which, in turn, can be re-employed in the pursuit of further profit (Margolis and Walsh 2003). The implicit goal in all of this seems to be to avoid 'waste'.

${ }^{6} \mathrm{Cf}$ the comments of Sorensen (2012: 180-1).
However, paradoxically, much of the preoccupation with reinvesting the surplus of labour into further growth seems to yield, on the level of the 'general economy', even more wasteful consumption of useless goods. As Rehn and O'Doherty (2007) point out, our contemporary lives are characterized by an endless array of unnecessary products and services. This proliferation of the excessive is indeed the complete opposite of the frugal 'economization' of costs, marginal utility and economic rationality (Rehn and O'Doherty 2007, p. 99). In the case of the middle and working class, their 'waste' emerges from a desire to become well amidst the complex interplay of individual, collective and systemic dynamics, which make no clear sense from a rational perspective. The fact that this expenditure is 'useless' is precisely the point. It is, as Zwier et al. (2015) describe, a kind of pressure valve, which allows the transformation of energy into growth to continue. Without this excessive release or expenditure, either catastrophically or gloriously, the system cannot continue.

What would it mean to approach sustainable development from the perspective of the 'general economy'? It amounts to a move away from scarcity and frugality to the acceptance of excess and 'waste' as an inevitable part of human society. Though 'waste' and 'expenditure' are related, there is also a possibility of considering certain types of expenditures as 'glorious', rather than catastrophic. Within the context of sustainable development, global interdependencies and growing need, excess may flow towards 'objective' need, but it also becomes available for the 'sovereign' consummation of 'subjective' desires, which allows for glorious expenditure on arts, cultural festivals and science for its own sake, rather than for utility (Zwier et al. 2015, p. 371). Sorensen (2012, p. 180) points out that Bataille's analysis of 'sovereignty' contains 'an irreducible and principled opposition between the 'objective' needs of the human being as such and the 'subjective' desire for sovereignty'. For Bataille, it is important to recognize the important role of this subjective desire in our economic activities. Bataille's admonitions in this regard may be more important ever as we collectively endeavour to shift towards a more sustainable general economy. He, however, allows us to go beyond criticism to a fundamental assessment of the paradoxes involved in being human.

Bataille's distinction between 'objective' need and 'subjective' desire may help us redefine our understanding of 'well-being' and, by extension, 'wealth'. Some researchers have calculated that there would be ample resources to feed and clothe every human being globally, if only the wealthier strata of global populations were willing to forsake certain luxury commodities such as perfume, alcohol and branded designer clothing. This seems to represent a clear-cut, rational case for an alteration of 
certain consumer behaviour. If people are essentially rational, calculating agents, why do they remain so unaffected by this kind of 'objective' calculative logic? The answer is surely that calculations of 'objective' need do not give us insight into, or control over, 'subjective' human desire.

In Bataille's political economy, we find an argument for moving away from a calculative economic logic towards an appreciation of the important role of 'subjective well-being' in our economic behaviour. From Bataille's perspective, human beings' tacit desire for 'sovereignty' inadvertently compels them to venture beyond the constraints of the calculable, controllable and predictable. As such, 'subjective' desire may hold the key to an alternative conception of 'wealth' and, by implication, 'well-being'. The question, however, remains, how can 'sovereignty', i.e. the squandering of energy and resources on unproductive and useless activities be reconciled with responsible stewardship of our planet's finite resources?

Of course Bataille, like almost all people at that time, assumed unlimited amounts of resources and energy and had no ecological concerns (Cf. Stoekl 2007, p. 39). Prima facie, Bataille's ideas about purposeless consummation of resources seem at the opposite of sustainable development. But the underlying sense of expenditure is sovereignty, the need to satisfy subjective desire: doing things for their own sake and not in a calculative way, for reasons of future profit. In Bataille's view, the energy delivered by the sun to biological beings is unlimited. Plants develop in an exuberant way. Animals sometimes expend more energy than they strictly need to survive. In human animals, this excess of energy ultimately ends up in pure expenditure that Bataille qualifies as a 'consciousness of nothing', which raises self-consciousness to a higher level (Bataille 1991: p. 190). The possibility of depleting energy (which does not mean oil or something similar, but rather time and effort) to 'nothing' is ultimately liberating (Geerts et al. 2014). Within contemporary capitalist societies though, 'subjective' desire has come to revolve around the consumption of commodities, but it doesn't need to be like this. Stoekl (2007, p. 58) clearly distinguishes Bataille's expenditure from the consumerist utopia. Expenditure is not about justifying the use 80 million barrels a day of oil, but accepting the 'wastage' of human effort and time.

The subjective desire of sovereignty is also present in the social, playful and creative parts of people's lives. Could we perhaps discard the notion of 'homo economicus' in favour of 'homo ecologicus'? That is to say, mankind as 'playful' living organisms instead of mankind as rational economic agents (Nodoushani 1999, p. 335). The point is not so much about destroying resources, but about being, like a sovereign, beyond calculation. Gift-giving is just another possibility of a sovereign detached attitude towards resources. Bataille explicitly mentions Marcel Mauss's famous essay: 'The Gift. The form and reason for exchange in archaic societies' as a major influence in the writing of his economic texts. ${ }^{7}$

In his interpretation of Bataille's contribution to sustainability discourses, Stoekl (2007, p. 50) also seems to believe that an embrace of the general economy may indeed serve the sustainability agenda, but not through frugality, restraint or calculation of costs. ${ }^{8}$ Instead, Bataille foresees a society that is sustained precisely because of the human collectivity's capacity for excessive and transgressive expenditure, in which individual energy becomes part of larger energy flows. His vision helps us envisage a world where we cease to rely on fossil fuels and other storable energy resources and instead rely on the sun's excessive energies and communities' ability to share it. Zwier et al. (2015) even argue that a sustainability strategy like the biobased economy will only succeed if it gives up on the scarcity model that underpins it and embraces the pressure valves of glorious expenditures. ${ }^{9}$

'Energy' is another way of thinking about the ownership of wealth. In a restrictive economy, it is something to be extracted, stored, used, recycled, always 'productively'. But this comes at a cost to society, both in cultural and in systemic terms, which is often unacknowledged. Banerjee's (2011, pp. 325-326) critique of 'management by extraction', 'management by exclusion' and 'management by expulsion' serves to illustrate what is at stake here: when certain natural resources are extracted and boundaries drawn around them, the free flow of energy is disrupted and blocked. For instance, when forests are treated as if they are no more than carbon sinks, their broader significance for local populations-not only as sources of food, livelihood, sources of medicine, housing, but also of culture, society, polity and economy-becomes obscured (Banerjee 2011, p. 326). In other cases, indigenous populations are displaced to make space for infrastructure and energy projects like dams. These forms of 'containment' disrupt the flow of energy as wealth within a general economy. More importantly, such restrictive perspectives on energy and the practices that follow in its wake destroy

\footnotetext{
${ }^{7}$ Cf. The first lines of 'The notion of expenditure'.

${ }^{8}$ Cf. Stoekl (2007, p. 122) discussion of Lisa Newton's position.

${ }^{9}$ One reviewer suggested that offering a 'non-calculative sovereignty' as an alternative to homo economicus is itself a strategic 'proto-calculative' move. That is indeed the case, to the extent that the concern for sustainable development is unavoidably future oriented. However, the move consists in arguing that narrow calculative profit-seeking (restrictive economy) without a sovereign, detached attitude (that leaves room for subjective desire and a broader sense of 'well-being') is not only denying a fundamental aspect of the general economy, it is doomed to fail because the incremental changes it allows seem hopelessly insufficient.
} 
our capacity to live in harmony with nature. If dimensions such as topophilia and solastalgia are important dimensions of well-being, we can see that such actions clearly undermine well-being, but not in a way that is completely calculable. A case in point is the way in which capitalist discourses around private property destroyed native populations' intimate relationship to the environment (Banerjee 2003). In such instance, the utility of the action is privileged, and the subjective desires, which lie in the interface of the individual and the cultural, are ignored.

Bataille (1991, p. 31) argues that the 'utility' of certain social practices (he for instance discusses lavish gift-giving practices in ancient culture) cannot be calculated, because the criteria by which they are judged are those of social 'acceptability'. From the perspective of the general economy, some resources must be consummated for people to experience a sense of sovereignty and social stability. In the process, energy seems 'wasted', yet subjective desires are fulfilled. We could therefore argue that instead of narrowly reducing 'development' to capital growth, it could be opened up to encompass phenomena such as the emergence of a new social structure, the solidification of existing social relations and the protection of beautiful spaces. ${ }^{10}$ The goal of these practices is to facilitate the flows of energy and resources within a society, which forms part of the ecosystem, rather than standing outside or against it. The criteria for sustainability projects then relate to their capacity to allow for the forms of cooperation, sharing, and energy circulation. Such practices may seem 'wasteful' from a utility point of view, yet they do not deplete energy sources, whether these sources be human, organic or inorganic. In addition, they fulfil certain important subjective desires.

The point of this paper is to illustrate that much of what we do in the area of sustainability may not be productive in terms of monetary outputs and growth. From the perspective proposed by Bataille (1991, p. 31), sustainability is not ultimately a question of 'utility', but one of 'acceptability', both in terms of how it facilitates social relationships and in terms of how it facilitates sovereign consummations. Following Bataille's logic, one could argue that sustainability emerges when social concern, economic concern and the harmony of the natural biosphere are equally essential in broadening our understanding of 'development'. As such, pursuing 'sustainable development', rather than just 'corporate sustainability', will require a much more complex analysis of the paradoxes inherent in sustainability. Placing

\footnotetext{
10 There is a link to be made between this broader vision on sustainability, beyond scarcity, and the recent debate about the role of 'the commons' in the economy. Leaving parts of the resources as 'commons' liberates us from short-term calculative profit seeking. Ostrom (1990) is maybe the better known reference. But see Dardot and Laval (2014) for a more radical view.
}

some forms of concern in the service of the calculative rationality of the other makes this impossible. Bataille makes a strong argument that one should approach the problems we face within political economy from the perspective of the 'general economy', because the 'particular' perspective is always trapped within perceptions of a lack of resources. He illustrates this in terms of the specific problem of poverty (Bataille 2011, p. 65ff). The inequalities in the world make it evident that some nations are in need of exudation, whereas others are in need of growth. Excess should therefore be directed to where growth is needed as a non-reciprocal exudation, a oozing forth that expects no return. The problem, however, is that as long as scarcity exist, at least in the mindset of the 'restrictive' economy, the scheme of 'moral accounting' will be in place and the question: 'What can we expect in return?' will inevitably be posed. There is such a preoccupation with ploughing all excess back into new opportunities for growth that the prospect of non-reciprocal expenditure does not present itself as defensible option. Reinserting a concern for social harmony means grappling with the incalculable. The paradoxes inherent in pursuing both individual autonomy and social relationships, both shortterm choice/freedom and long-term respect for nature, defies categorization. It challenges the 'utility' that our systems of moral accounting rely on. But if we take it seriously enough, it might make exudation, the oozing forth and the fulfilment of subjective desire possible again - even if, and precisely because-there is no financial benefit associated with it. It would also allow us to integrate the hedonic (the pleasurable), with eudaimonic (the meaningful) as mutually reinforcing aspects of becoming well (Küpers 2005, p. 229).

\section{Conclusion}

Where does this leave us? Firstly, understanding the moral metaphors that inform our normative arguments within the business realm helps us gain insight into our most basic assumptions, both from a cognitive perspective and from a discursive perspective. However, simply understanding the limitations of these basic orientations is unlikely to lead to change. As Clarke et al. (2014, p. 248) point out, though metaphors have great heuristic value, they also become obstacles to greater understanding if mindlessly promulgated in theory. In order to rethink our approach to sustainable development, new perspectives are necessary, and alternative ways of living must be considered as viable options. It is in this regard that Bataille and critical management scholars like Banerjee $(2003,2008$ a) are helpful in reminding us that a different orientation to well-being is indeed possible and crucial to consider if one wants to 
provide a better account of the paradoxes inherent in pursuing sustainability.

If we could redefine 'well-being = wealth' as 'wellbeing $=$ sovereignty $=$ flourishing', new possibilities in terms of understanding sustainable development may emerge. Some radical mind shifts may, however, be necessary. 'Wealth', for instance, would have to be redefined as opportunities for sovereign consummation, rather than the sum total of what we extract, contain and monetize, i.e. the resources we accumulate for consumption. Most importantly, we need to widen our perspective beyond the restrictive calculative logic that characterizes our thinking. This has an impact on our linguistic employment of metaphor and argument when it comes to sustainability. As Bataille (1991, p. 30) explains: 'life suffocates within limits that are too close'. What seems to be needed is the re-establishment of energy flows, beyond narrow interests of calculating economic agents or nation states.

New connections with others that challenge mainstream interpretations of wealth are therefore necessary. Banerjee's (2011, p. 330) proposal that we engage in 'translocal resistance' may be a step in the right direction. 'Translocality' refers to 'the multiplicity of local spaces and actors and their interrelationships in a global world'. Translocal spaces may help us to create new spaces of agency and overcome the preoccupation with the interests of the nation state and the vested (corporate) interests of many national governments. State and market forces tend to focus on the protection of individual rights at the expense of communal rights. Banerjee alludes to the notion of 'translocal sovereignty', but this concept has yet to be developed theoretically and politically. Our redefinition of wealth calls for translocal consummations and sharing of resources freely, outside of the scarcity motives of the restrictive economy.

This would mean that resources, like energy, could be exuded in whichever direction it is needed. Through a glorious expenditure of energy, we move closer to the integral pheno-practice of well-being that Küpers (2005) describes. It is a not something that one individual or firm 'possesses', but instead a process of becoming-well as individual, cultural and systemic variables interact over time.

Recognizing the important role of 'subjective desire' in human motivation allows us to think about CSR as a sovereign act that requires no reciprocity, yet must meet the standard of acceptability from a translocal perspective, taking into consideration the interaction between individual, cultural and systemic variables that play in role in peoples' 'becoming-well' (Küpers 2005). This more inclusive relational ethics may go a long way towards addressing the objection that corporate sustainability is more geared towards sustaining capital growth within corporations than enabling the energy flows of people and ecosystems. It may also help us to move beyond the kind self-serving, calculative CSR that tends to support only those stakeholders who have monetary power or some other power to affect corporate interest. It could change the way we talk about and approach sustainable development: the emphasis would shift towards social acceptability, or recognizing and exploiting opportunities for non-utilitarian sovereign consummation in the way we relate to one another and the non-human world. Ultimately, sustainable development should be motivated by a concern for flourishing and less preoccupied with the 'business case'.

There is an urgent need to focus on protecting 'living matter' (fauna, flora and ecosystems), rather than 'dead matter' (capital and commodities) (Banerjee 2006). Banerjee (2008b, p. 1543) sketches a dismal picture of what he calls 'necrocapitalism': 'practices of organizational accumulation that involve violence, dispossession, and death'. One way to reframe our conception of 'wealth' as the accumulation of commodities for consumption is therefore to draw attention to the way in which living, thriving things are rendered lifeless in this process of commodification. The interaction, over time, of the various quadrants of wellbeing variables (as highlighted in Fig. 1) allows us to understand the emergence of 'subjective' desires and to allow for expenditures that are essential to any kind of sustainable development. Instead of merely criticizing capitalism for its current form, our challenge is to reframe our thinking in more positive ways and to help find our more social and subjective desires to find expression.

It may be unlikely that we can escape the "moral accounting' that underpins so much of our moral reasoning, but we can at least attempt to rethink its terms. From our analysis of the metaphors employed within the sustainable development arena, such as 'natural capital' and 'industrial ecology', it seems that we have allowed the 'dead matter' of capital to replace a concern for the 'living matter' of nature/ecology in all of our equations, even if this had not been the original intention. As such, our 'moral accounting' no longer serves to protect what is living. The paradoxical effect of such calculations is that it undermines what it seeks to protect. Alternatives to 'moral accounting' could only become possible if we (1) acknowledge people's aspiration to sovereignty, i.e. their 'subjective' desire as a very important part of people's sense of well-being and wealth and (2) take a general rather than a restrictive view of the economy.

Advocacy for sustainable business practices is often based on the implicit assumption that those involved are principally motivated by financial self-interest. Following Bataille, we challenged this assumption. We propose instead that, apart from securing the basic resources necessary to sustain life, human beings are motivated by a 'subjective' desire for sovereign consummation. That is to 
say, to act in ways that are not determined by considerations of utility, efficiency or productivity. While such considerations may be necessary to provide and secure the basic resources necessary to sustain life, it is ultimately opportunities for sovereign consummation that makes life feel worth living. It is our contention that the importance of the former is regularly absolutized, while the latter is under-emphasized. Why should this be ignored as a motive in our efforts to create more sustainable business practices? People's 'subjective' desires are routinely used to sell them commodities that they do not need and that cannot be justified on rational, calculative grounds. Why should these desires not be brought to bear on our relationship with nonhuman nature? In fact, we would argue that this happens all the time. Why else would people decide to save a forest for the sake of preserving an endangered species of diminutive frogs-thereby willingly foregoing the considerably revenue that could potentially have been generated from the sale of timber or the produce cultivated on cleared land?

The world's first nature reserve-Yellow Stone-in the USA was created simply because those involved found the landscape beautiful and wanted it to remain unspoilt. There has perhaps never been a time or a place where pragmatic, utilitarian values have predominated more than the nineteenth century, western USA. If such an act of sovereign consummation can be undertaken in a context as unprepossessing as that, why should we doubt the power or efficacy of the deeply human impulse behind it? Every year hundreds of people attempt to scale Everest-the highest mountain in the world. Many of them will spend their life savings to do so. A small number will succeed. One in ten will die in the attempt. And when you ask them why they would spend and risk so much simply for the sake of standing on top of a mountain for a few minutes, most will simply echo the words of Edmond Hillary, the first man to conquer Everest: 'Because it's there'. Because, in truth, it makes no sense from a rational, calculative, utilitarian point of view. Like so many of the things that make us feel most truly alive, it is an act of pure, sovereign consummation.

So perhaps we should try bringing people to the mountain. Show them the pristine natural landscape with its clear lakes, towering old-growth forest and teaming meadows. Then show them the jumble of profitable toxic reservoirs, blackened smokestacks and piles of broken debris that could replace it. Give them an opportunity to do something that makes no practical sense.

\section{Compliance with Ethical Standards}

Conflict of interest Prof. Painter-Morland declares that she has no conflict of interest. Prof. Demuinjck declares that he does not have a conflict of interest. Dr. Ornati declares that she has no conflict of interest.
Ethical Approval This article does not contain any studies with human participants or animals performed by any of the authors.

Open Access This article is distributed under the terms of the Creative Commons Attribution 4.0 International License (http://crea tivecommons.org/licenses/by/4.0/), which permits unrestricted use, distribution, and reproduction in any medium, provided you give appropriate credit to the original author(s) and the source, provide a link to the Creative Commons license, and indicate if changes were made.

\section{References}

Abramovitz, M. (1959). The allocation of economic resources. Redwood City, CA: Stanford University Press.

Akerman, M. (2005). What does "natural capital" do? The role of metaphor in economic understanding of the environment. Environmental Education Research, 11(1), 37-52.

Alvesson, M. (1993). The play of metaphors. In John Hassard \& Martin Parker (Eds.), Postmodernism and organizations. London: Sage.

Audebrand, L. (2010). Sustainability in strategic management education: The quest for new root metaphors. Academy of Management Learning \& Education, 9(3), 413-428.

Banerjee, S. B. (2003). Who sustains whose development? Sustainable development and the reinvention of nature. Organization Studies, 24(1), 143-180.

Banerjee, S. B. (2006). Live and let die: Colonial sovereignties and the deathworlds of necrocapitalism. Borderlands, 5(1). http:// www.borderlands.net.au/vol5no1_2006/banerjee_live.htm. Accessed 23 March 2015.

Banerjee, S. B. (2008a). Corporate social responsibility: The good, the bad and the ugly. Critical Sociology, 34(1), 51-74.

Banerjee, S. B. (2008b). Necrocapitalism. Organization Studies, 29, $1541-1562$.

Banerjee, S. B. (2011). Voices of the governed: Towards a theory of the translocal. Organization, 18, 323-344.

Bataille, G. (1976). Oeuvres complètes (Vol. VIII). Paris: Gallimard.

Bataille, G. (1991). The accursed share (Vol. I). New York: Zone Books.

Bataille, G. (2011). La Part maudite. Paris: Les éditions de minuit.

Baudrillard, J. (2010). Quand Bataille attaquait le principe métaphysique de l'économie. Lignes, 31, 149-154.

Blanchflower, D. G., \& Oswald, A. J. (2008). Is well-being U-shaped over the life cycle? Social Science and Medicine, 66, 1733-1749.

Blewitt, J. (2005). Education for sustainable development, natural capital and sustainability: Learning to last. Environmental Education Research, 11, 71-82.

Burroughs, J. E., \& Rindfleisch, A. (2002). Materialism and wellbeing: A conflicting values perspective. Journal of Consumer Research, 29(3), 348-370.

Christopher, A. N., Saliba, L., \& Deadmarsh, E. J. (2009). Materialism and well-being: The mediating effect of locus of control. Personality and Individual Differences, 46(7), 682-686.

Chuluun, T., Graham, C., \& Myanganbuu, S. (2014). Happy neighbours are good for you, wealthy ones are not: Some insights from a first study of well-being in Mongolia. Global economy and development working paper, 76.

Clarke, J., Holt, R., \& Blundel, R. (2014). Re-imagining the growth process: (Co)-evolving metaphorical presentations of entrepreneurial growth, entrepreneurship and regional development. An International Journal, 26(3-4), 234-256.

Cornelissen, J., Oswick, C., Christensen, L., \& Phillips, N. (2008). Metaphor in organizational research: Context, modalities and 
implications for research-Introduction. Organization Studies, 29(1), 7-22.

Dardot, P., \& Laval, C. (2014). Commun. Essai sur la révolution au XXIe siècle. Paris: La Découverte.

DeNeve, J., \& Oswald, A. (2012). Happiness pays: Measuring the effect of subjective well-being on later income using sibling fixed effects. In Royal Economic Society's annual conference at the University of Cambridge.

Diener, E. (2012). New findings and future directions for subjective well-being research. American Psychologist, 67(8), 590.

Dolan, P., \& Metcalfe, R. (2012). Measuring subjective well-being: Recommendations on measures for use by national governments. Journal of Social Policy, 41(2), 409-427.

Dorfman, B. (2002). The accursed share: Bataille as historical thinker. Critical Horizons, 3(1), 37-71.

Easterlin, R. A. (1974). Does economic growth improve the human lot? Some empirical evidence. In P. A. David \& M. W. Reder (Eds.), Nations and households in economic growth: Essays in honor of Moses Abramovitz. New York: Academic Press.

Frey, B., \& Stutzer, A. (2002). What can economists learn from happiness research? Journal of Economic Literature, 40(2), 402-435.

Geerts, R.-J., Gremmen, B., Jacobs, J., \& Ruivenkamp, G. (2014). Towards a philosophy of energy. Scientiae Studia, 12, 105-127.

Gómez-Bezares, F., Przychodzen, W., \& Przychodzen, J. (2016). Corporate sustainability and shareholder wealth-Evidence from British companies and lessons from the crisis. Sustainability, 8, 276. doi:10.3390/su8030276.

Gough, S. (2005). Rethinking the natural capital metaphor: Implications for education and learning. Environmental Education Research, 11(1), 95-114.

Graham, C. (2008). Happiness and health: Lessons and questions for public policy. Health Affair, 27(1), 72-87.

Graham, C. (2010). Adaptation amidst prosperity and adversity: Insights from happiness studies from around the world. The World Bank Research Observer, 26, 105-137.

Graham, C. (2012). The pursuit of happiness: An economy of wellbeing. Washington: Brookings Institution Press.

Graham, C., Eggers, A., \& Sukhtankar, S. (2004). Does happiness pay?: An exploration based on panel data from Russia. Journal of Economic Behavior \& Organization, 55(3), 319-342.

Graham, C., \& Nikolova, M. (2013). Does access to information technology make people happier? Insights from well-being surveys from around the world. The Journal of Socio-Economics, 44, 126-139.

Griffin, J. (1986). Well-being. Its meaning, measurement and moral importance. Oxford: Clarendon Press.

Griffin, J. (1991). Against the taste model. In J. Elster \& J. Roemer (Eds.), Interpersonal comparisons of well-being (pp. 45-69). Cambridge: Cambridge University Press.

Guillaume, M. (1987). Bataille économiste: Une fresque grandiose des sociétés humaines. Magazine littéraire, 243, 30-31.

Hahn, T., Pinkse, J., Preuss, L., \& Figge, F. (2015a). Cognitive frames in corporate sustainability: Managerial sense-making with paradoxical and business case frames. Academy of Management Review, 4015, 18-42.

Hahn, T., Pinkse, J., Preuss, L., \& Figge, F. (2015b). Tensions in corporate sustainability: Towards an integrative framework. Journal of Business Ethics, 127(2), 297-316.

Hart, C. (2008). Critical discourse analysis and metaphor: Toward a theoretical framework. Critical Discourse Studies, 5(2), 91-106.

Hausman, D. (2012). Preference, value, choice, and welfare. Cambridge: Cambridge University Press.

Hess, G. (2010). The ecosystem: Model or metaphor? Journal of Industrial Ecology, 14(2), 270-285.

Johnson, M. (2007). The meaning of the body. Aesthetics of human understanding. Chicago: The University of Chicago Press.
Kahneman, D., \& Deaton, A. (2010). High income improves evaluation of life, but not emotional well-being. Proceedings of the National Academy of Science, 107(38), 16489-16493.

Küpers, W. (2005). Phenomenology and integral pheno-practice of embodied well-be(com)ing in organizations. Culture and Organization, 11(3), 221-231.

Lakoff, G., \& Johnson, M. (1999). Philosophy in the flesh: The embodied Mind and its challenge to Western thought. New York: Basic Books, Kindle Edition.

Margolis, J. D., \& Walsh, J. P. (2003). Misery loves companies: Rethinking social initiatives by business. Administrative Science Quarterly, 48(2), 268-305.

Millennium Ecosystem Assessment. (2005). http://www.millenniu massessment.org/en/index.html. Accessed 20 June 2017.

Miesen, H. (2009). Love is all you need: Social relatedness needs, materialism and subjective well-being. Paper presented at the happiness and social relatedness goods conference in Venice, Italy, 11-13th June.

Milne, M., Kearins, K., \& Walton, S. (2006). Creating adventures in wonderland: The journey metaphor and environmental sustainability. Organization, 13(6), 801-839.

Mitchell, I. K., \& Saren, M. (2008). The living product-Using the creative nature of metaphors in the search for sustainable marketing. Business Strategy and the Environment, 17(6), 398-410.

Morgan, G. (1980). Paradigms, metaphors, and puzzle solving in organization theory. Administrative Science Quarterly, 25(4), $605-622$

Nietzsche, F. (1886/1973). On truth and lie in the extramoral sense. In: W. Kaufman (Ed.), The Portable Nietzsche. New York: Viking Press.

Nodoushani, O. (1999). A postmodern theory of general economy: The contribution of Georges Bataille. Studies in Cultures, Organizations \& Societies, 5(2), 331.

Ostrom, E. (1990). Governing the commons. The evolution of institutions for collective action. Cambridge: Cambridge University Press.

Painter-Morland, M. J., \& ten Bos, R. (2016). Should environmental concern 'pay off? A Heideggerian perspective. Organization Studies. doi:10.1177/0170840615604502.

Rehn, A., \& O'Doherty, D. (2007). Organization: On the theory and practice of excess. Culture and Organization, 13(2), 99-113.

Ryan, R., \& Sapp, A. (2007). Basic psychological needs: a selfdetermination theory perspective on the promotion of wellness across development and cultures. In I. Gough \& A. McGregor (Eds.), Wellbeing in developing countries: from theory to research. Cambridge: Cambridge University Press.

Schaltegger, S., \& Hörisch, J. (2015). In search of the dominant rationale in sustainability management: Legitimacy or profitseeking? Journal of Business Ethics. doi:10.1007/s10551-0152854-3.

Sen, A. (1999). The possibility of social choice. The American Economic Review, 89(3), 349-378.

Sorensen, A. (2012). On a universal scale: Economy in Bataille's "general economy". Philosophy and Social Criticism, 38(2), 169-197.

Spence, C., \& Thompson, I. (2009). Resonance tropes in corporate philanthropy discourse. Business Ethics: A European Review, 18(4), 372-388.

Stigler, G., \& Becker, G. (1977). De Gustibus non est Disputandum. American Economic Review, 67(2), 76-90.

Stiglitz, J. E., Sen, A., \& Fitoussi, J. P. (2009). Report by the commission on the measurement of economic performance and social progress. Paris: OECD.

Stoekl, A. (2007). Bataille's peak: Energy, religion, and postsustainability. Minneapolis: University of Minnesota Press. 
Summers, J., \& Smith, L. (2014). The role of social and intergenerational equity in making changes in human well-being sustainable. AMBIO: A Journal of the Human Environment, 43(6), 718-728.

Tay, D. (2010). Revisiting metaphor types as discourse strategies: The case of psychotherapeutic discourse. Text \& Talk, 30(4), 445-463.

Taylor, M. (2004). Confidence games: Money and markets in a world without redemption. Chicago: University of Chicago Press.

Van der Deijl, W. (2017). Are measures of well-being philosophically adequate? Philosophy of the Social Sciences, 47(3), 209-234.

Vansteenkiste, M., Duriez, B., Simons, J., \& Soenens, B. (2006). Materialistic values and well-being among business students:
Further evidence of their detrimental effect. Journal of Applied Social Psychology, 36(12), 2892-2908.

Winnett, A. (2005). Natural capital: Hard economics, soft metaphor? Environmental Education Research, 11(1), 83-94.

World Commission on Environment and Development (WCED). (1987). Our common future (p. 43). Oxford: Oxford University Press.

Zwier, J., Blok, V., Lemmens, P., \& Geerts, R. J. (2015). The ideal of a zero-waste humanity: Philosophical reflections on the demand for a bio-based economy. Journal of Agricultural and Environmental Ethics, 28(2), 353-374. 